\begin{tabular}{|c|c|c|c|c|c|}
\hline $\begin{array}{l}\text { Clinic } \\
\text { Category }\end{array}$ & $\begin{array}{c}\text { Mean } \\
\text { age } \\
\text { (years) }\end{array}$ & $\begin{array}{c}\text { Number } \\
\text { of } \\
\text { Patients }\end{array}$ & $\begin{array}{c}\text { Mean Index of } \\
\text { Multiple } \\
\text { Deprivation rank } \\
\text { (1= most deprived, } \\
32,844=\text { least } \\
\text { deprived) }\end{array}$ & $\begin{array}{l}\text { Percentage } \\
\text { of patients } \\
\text { in least } \\
\text { deprived } \\
\text { quintile }\end{array}$ & $\begin{array}{c}\text { Percentage } \\
\text { of patients } \\
\text { in most } \\
\text { deprived } \\
\text { quintile }\end{array}$ \\
\hline Allergy & 4.66 & 4088 & 10,719 & $3.57 \%$ & $36.91 \%$ \\
\hline Asthma & 7.54 & 796 & 9327 & $2.14 \%$ & $41.08 \%$ \\
\hline CFS/ME & 14.66 & 1630 & 18,274 & $26.20 \%$ & $14.66 \%$ \\
\hline Diabetes & 11.17 & 663 & 18,369 & $24.13 \%$ & $13.42 \%$ \\
\hline Endocrine & 13.61 & 4538 & 15,254 & $15.93 \%$ & $22.17 \%$ \\
\hline Epilepsy & 7.92 & 865 & 10,864 & $4.97 \%$ & $36.99 \%$ \\
\hline $\begin{array}{l}\text { General } \\
\text { Paediatrics }\end{array}$ & 5.73 & 9846 & 10,132 & $3.04 \%$ & $39.15 \%$ \\
\hline Rapid Access & 4.05 & 9714 & 9706 & $2.28 \%$ & $39.53 \%$ \\
\hline
\end{tabular}

appointment attendance. The mean Index of Multiple Deprivation rank for each postcode was obtained. The proportion of patients in the most and least deprived quintiles were also calculated. 229 postcodes were unmatched.

Results

Conclusions The socioeconomic profile of secondary care clinics for Allergy, Epilepsy and General Paediatrics broadly matched the profile of our hospital inpatient population (4.4\% and $37.9 \%$ in the least and most deprived quintiles). Secondary care Asthma and Rapid Access clinics were slightly more skewed towards patients from more deprived areas. In contrast, Endocrine, Diabetes and CFS/ME clinics showed a much higher proportion of patients from more affluent backgrounds- perhaps reflecting a larger proportion of these patients who live outside our local area. Further research will now be conducted to determine the extent to which these findings may also reflect unmet need and difficulty in accessing more specialist clinics for families living in more deprived areas.

\section{P16 A USEFUL TECHNIQUE FOR PATIENT ACTIVATION AND ENGAGEMENT IN YOUNG ADULTS WITH CONGENITAL HEART DISEASE: INSTRUCTIONAL CONVERSATION USING THE CONGENITAL HEART HEALTH ACTIVATION TRANSITION TOOL}

${ }^{1} \mathrm{KN}$ Lopez*, ${ }^{2} \mathrm{DK}$ Lovick, ${ }^{2} \mathrm{NS}$ Broussard, ${ }^{1} \mathrm{P}$ Ermis. ${ }^{1}$ Pediatrics, Baylor College of Medicine, Houston, USA; ${ }^{2}$ Pediatrics, Texas Children's Hospital, Houston, USA

\subsection{6/bmjpo-2019-RCPCH-SAHM.22}

Aims Adolescents and young adults (AYA) with congenital heart disease (CHD) are a high-risk group particularly during the transition period from pediatric to adult care. We aimed to create a clinic-based tailored CHD transition program to improve adolescent knowledge and activation, increase participation in shared-decision making, and facilitate patient empowerment through Instructional Conversations (IC).

Methods We conducted a needs assessment with key stakeholders (pediatric and adult cardiologists, parents, and adolescents with $\mathrm{CHD}$ ) to identify potential barriers to transition. A three-pronged approach was taken to spearhead transition education: (1) Streamlining dedicated transition visits; (2) Creating individualized learning plans (ILP) to encourage shared decision making and patient engagement: and (3) Utilizing motivational interviewing (MI) and instructional conversation (IC) to administer a novel patient activation tool: CHHATT- The Congenital Heart Health Activation Transition Tool.

Results Six Plan-Do-Study-Act (PDSA) cycles were conducted and included streamlining educational/assessment materials, modifying teaching style, implementing MI and IC, and creating the CHHATT tool. During PDSA cycles, three major themes emerged regarding patient activation and engagement. First, families better received transition services if given advanced notice. Thus, we built separate clinic visits for program introduction (14 year old) and serial education/ training visits (15 year old). Second, having a streamlined script for education of various CHD diagnoses and creating ILPs resulted in increased patient engagement and shared decision-making. Third, patient self-assessments poorly revealed true knowledge deficits. MI was used to reveal these deficits through creation of a CHHATT tool, which reveals knowledge/skills gaps and reinforces education through guided IC. Patients demonstrated increased confidence when using the CHHATT to teach-back to parents and ask physician questions. Parents' verbalized satisfaction in the increased empowerment teens demonstrated after serial visits using CHHATT.

Conclusion We created a CHD transition program for AYA with streamlined serial education, individualized learning plans, and motivational interviewing and instructional conversation. Patients demonstrated increased activation and engagement using our novel tool CHHATT. We strive to lead transitional clinical care and further patient success by (1) introducing additional assessment tools for health literacy and resilience and (2) guiding clinical practice by sharing our sustainable/billable program model for CHD transition programs.

\section{P17 FACTORS ASSOCIATED WITH LOW PHYSICAL ACTIVITY AMONG IN-SCHOOL ADOLESCENTS}

AA Osiberu*, NOS Atulomah. Department of Public Health, Babcock University, Ilishan, Nigeria

\subsection{6/bmjpo-2019-RCPCH-SAHM.23}

Introduction/Aim Despite the established health benefits of physical activity, the health risks of inactivity and the various interventions to encourage physical activity, a substantial proportion of young people remain insufficiently active. Studies have attempted assessing factors associated with physical activity but do not provide explanations for the dynamics of underlying factors. Similarly, interventions do not show significant difference in control. This study therefore was undertaken to determine factors associated with physical activities among the target population using health promotion theories to provide explanations of their dynamics.

Methods The study was a community-based cross-sectional study which employed a validated instrument developed to measure level of physical activity, assess patterns of sedentary lifestyle and personal-level and environmental-level dispositions of the respondents towards physical activity. Cronbach's alpha Internal consistency measure of the instrument was 0.814 and all statistical tests were set at $p=0.05$ level of significance as cut off. 